\title{
Alternative life-loss rates for failures of large concrete and masonry dams in mountain regions of OECD countries
}

\author{
A. Kalinina, M. Spada \& P. Burgherr \\ Laboratory for Energy Systems Analysis, Paul Scherrer Institute, Switzerland
}

\begin{abstract}
High safety standards for dams in Switzerland require continuous assessment of their structural stability and effectiveness of warning system. Therefore, risk assessment needs to be performed for estimation of consequences, e.g. Life Loss (LL), in case of a dam accident. With the life-loss estimation methods available nowadays, e.g. the LIFESim system, physical processes within the specific dam-failure event can be simulated. This study demonstrated the importance of adjusting the LL rates in LIFESim to reflect study-specific characteristics of the dam type and failure mode. In particular, for application to Swiss dams, alternative LL rate distributions were built based on historical events of concrete and masonry dams in the mountain regions of OECD countries. The alternative LL rates distributions had different shapes and frequency ranges than those recommended in LIFESim. A simulation example of a hypothetical dam failure showed that the alternative and recommended LL rates lead to different LL estimates.
\end{abstract}

\section{INTRODUCTION}

Switzerland is the country with the highest density of dams in the world. Most of the dams were built to generate hydro-electricity ( $90 \%$ of all dams), but they also play an important role as flood control facilities. Swiss dams are constructed and operated under high safety standards. Historically no failures of Swiss dams have occurred; where a dam failure can be defined as a collapse or movement of part of a dam or its foundation leading to a disability of the dam to retain water (ICOLD, 2016). However, the ageing of many facilities and the increasingly stricter safety standards require that dam engineers and operators need to regularly assess and update potential risks associated with dams. An example is the assessment of consequences in terms of Life Loss (LL) due to a hypothetical dam failure. The results of such a risk assessment can help to justify, for example, costly facility upgrades or investments in the warning system required for risk mitigation.

To provide a transparent and quantifiable way to determine consequences, e.g. LL, associated with dam failures and subsequent floods, various methods and models are available nowadays.

\subsection{Methods for life-loss estimation}

Methods for LL estimation differ in complexity and modeling principles. Most of the approaches are purely empirical and LL estimates are based on regressions of Population At Risk (PAR) as a function of the whole downstream population and heterogeneous Warning time (Wt) (e.g. Lee et al., 1986; Brown and Graham, 1988). Another approach by Graham (1999) is more sophisticated and provides LL rates for a mix of subgroups of PAR based on $\mathrm{Wt}$, flood severity, and warning effectiveness.

However, empirical approaches have limitations, which can be summarized as following (McClelland and Bowles, 2002). Firstly, empirical methods do not differentiate between characteristics of the dam failure (e.g. breach propagation or instantaneous failure) and flood severity, which might lead to the underestimation of the impact of the flood. Secondly, information on PAR, building structures, flow quantities, etc. represent averages and is not site specific. This strongly affects the LL results, because they depend on the gender and age distribution of PAR (Salvati et al., 2018). Thirdly, evacuation is not modelled and $\mathrm{Wt}$ is considered as a single value, which affects the number of people that are exposed to the flood and in turn the LL estimates.

To overcome these limitations in LL estimation, it is necessary to simulate physical processes and interactions, which cannot be achieved with empirical methods only. For this purpose, complex Geographical Information Systems (GIS)-based models have been developed in recent years allowing the dynamic simulation of flood consequences, including estimation of LL due to a dam failure. In contrast to empirical methods, these models estimate LL using modules with databases about evacuation, warning time, and loss of shelter to consider site-specific conditions. The most known 
models are the Life Safety Model (LSM) (British Columbia, 2006) and the HEC-LifeSim model (USACE, 2017a). LSM is an agent-based model requiring detailed information for simulation, and thus it is more suitable for studies that model the behavior of the individual receptor (i.e. microscale simulation of the impact on a person or vehicle). In contrast, LIFESim scales up the simulation from the microscale to the mesoscale, i.e. simulation for the zone; therefore, it is more suitable for LL estimation for the specific area downstream of the dam.

\subsection{Study goals}

As discussed, the application of physically-based models in dam risk assessments could lead to better LL estimation. However, available models were developed by U.S. institutions that used LL rates empirically derived from historical data on flood events that mostly happened in the USA (see Section 2.2). The direct application of these LL rates to Switzerland would provide a potentially questionable approximation, since it has been shown that accident frequency and severity strongly depend on dam characteristics and location (Kalinina et al., 2017).

Therefore, this study aims to develop LL-rate distributions that can be considered representative for the topographical conditions and characteristics of dams in Switzerland. These LL rate distributions are used in modular LL estimation models to indicate proportion of life loss, $\mathrm{P}$, for different flood zones and the corresponding relative frequency of exceeding this rate. To build these distributions historical failures of concrete and masonry dams in mountain regions of OECD countries were used, which can also be considered representative for Switzerland. Furthermore, the calculated LL rate distributions were used as input to the HEC-LIFESim model to simulate the LL resulting from an instantaneous dam failure. In this way it was possible to demonstrate the robustness of the physically-based model and the sensitivity of LIFESim simulation results to different LL rates. Therefore, this study provides quantitative insights on the recommendation of $\mathrm{McClelland}$ and Bowles (2002) that the historical observations underlying the method for LL estimation should be adjusted according to the type of event that is likely for a particular study setting.

\section{METHOD}

In this section, the spatial modular software HECLIFESim (USACE, 2017a) is introduced. Then, the motivation for developing alternative LL rates to be applied for failures of large concrete and masonry dams in mountain areas is explained and the methodology for constructing the alternative LL-rate distributions is given. Finally, a simulation example, that will be built to demonstrate the effect of different LL rates on LL estimates, is described.

\subsection{HEC-LIFESim software}

HEC-LIFESim (or LIFESim throughout this article) is a software developed by the Hydrologic Engineering Center (HEC) of the U.S. Army Corps of Engineers (USACE, 2017a). LIFESim is a spatial dynamic system for modeling life loss or economic consequences of a natural, dam or dike flood event. LIFESim is a modular system consisting of four modules built around databases. The modules exchange data through a geo-database with various information layers and tables, as shown in Figure 1.

Within LIFESim the aforementioned data can be combined with other GIS layers such as ESRI maps (ESRI, 2017), which allows for simulations that can represent real world conditions in a more realistic and accurate manner. In other words, LIFESim can overcome some of the limitations of the purely empirical approaches for modeling LL of a dam failure.

The four modules of the LIFESim system are represented as blocks in Figure 1: 1) flood routing module, 2) loss of shelter module, 3) warning and evacuation module, and 4) loss of life module. The flood routing module of LIFESim interfaces with an existing flood routing model (e.g. HEC-RAS 5.0.3 (USACE, 2017c)) and using hydraulic and

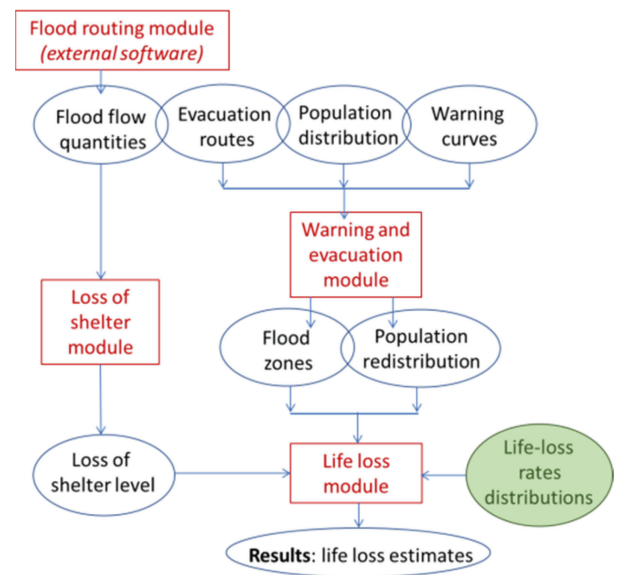

Figure 1. Simplified representation of the LIFESim approach for LL estimation (modified from Bowles, 2007). 
timing editor it imports time series of flow quantities from hydraulic data source, e.g. depth time series at different points of the inundated area.

The loss-of-shelter module simulates the exposure of people in buildings during the flood event. For this, different flood zones are assigned to buildings and levels of buildings in the inundated area. In each flood zone, the physical flood environment is different, which is reflected in different historical rates of life loss. The three flood zones are defined by McClelland and Bowles (2000) by the interplay between available shelter and local flood depths and velocities, and can be summarized as follows:

- Chance zones in which flood victims are typically swept downstream or trapped underwater, and survival depends largely on chance;

- Compromised zones in which the available shelter has been severely damaged by the flood, increasing the exposure of flood victims to violent floodwaters.

- Safe zones are typically dry, exposed to relatively quiescent floodwaters, or exposed to shallow flooding unlikely to sweep people off their feet.

As input for the loss of shelter module, LIFESim utilizes the datasets of flow quantities in the simulation domain and the structure inventories obtained, for example, from HAZUS MH data (Federal Emergency Management Agency, 2003). Stability criteria for structures are set by default in LIFESim and can be changed for the specific study.

The warning and evacuation module simulates the spatial distribution of the population at risk from its initial distribution at the time when the warning is issued, to a new distribution with assigned flood zones when the flood arrives. For this module, the following information is required: GIS information on road layout, for example, from Highway Capacity Manual (TRB, 2000), information about population, for example, from HAZUS MH data (Federal Emergency Management Agency, 2003); evacuation destinations and emergency planning zones, which are location-specific and available as shape-files. Other evacuation parameters are set by default in LIFESim and can be changed for the specific study.

Finally, the loss-of-life module determines LL using the results of the aforementioned three modules. Based on the assigned flood zone categories (the loss-of-shelter module) and the value of PAR in this category (defined by the interplay between the flood map and the building inventory data), life-loss estimates are assessed using LL-rate distributions (McClelland and Bowles, 2002). For the simulations in this study, the recommended distributions were changed to alternative ones; this is indicated in Figure 1 in green and explained further in the text.

\subsection{LL rates distributions recommended in LIFESim}

For the estimation of LL, LIFESim recommends LL rates distributions developed by McClelland and Bowles (2002). To calculate the rates, the total PAR was determined and further divided into subgroups (subPAR), which help to customize the model to local conditions and to have homogeneous data for distinct areas. Three flood zones were then identified for each subPAR using the information about warning and flood severity. Finally, by estimating the ratio between the number of fatalities and the number of people in the particular flood zone of the particular subPAR, the P value was calculated for each case. Using the calculated P, the LL rates distributions were built for each flood zone (recommended distributions in Figure 3).

To construct the LL rates distributions, 38 unique flood events with 179 associated subPARs were used (Table 1). These events can be classified in three types: natural floods, floods due to a dam failure and floods due to a dike failure. Flood events due to a dam failure can be further classified in subgroups based on the dam type, among which the subgroup of floods resulting from failures of embankment dams is the largest. A similar prevalence of embankment dam failures was also found in datasets used to empirically estimate the dam-failure outflow in previous studies (Froehlich, 1995; Costa, 1985). In both cases, this can be explained by the fact that these dams commonly failed gradually; thus, data on characteristics (flow quantities, people) could be recorded. In contrast, instantaneous failures common for concrete dams give no chance to record detailed data, resulting in 8 events with 26 subPAR in Table 1 .

Table 1. Flood events used by McClelland and Bowles (2002).

\begin{tabular}{lrrl}
\hline & \multicolumn{2}{l}{ Number of } & \\
\cline { 2 - 3 } Type of event & Event & subPAR & Topography \\
\hline $\begin{array}{l}\text { Flood (river, flash, } \\
\quad \text { alluvial fan) }\end{array}$ & 10 & 25 & - \\
$\begin{array}{l}\text { Dike } \\
\text { Dam: }\end{array}$ & 1 & 1 & - \\
- Embankment & 27 & 153 & - \\
- Buttress & 16 & 121 & - \\
- Gravity & 1 & 1 & mountain \\
& 2 & 8 & mountain \\
& 4 & 11 & open/relatively \\
- Arch & & & flat area \\
- Tailing & 1 & 6 & mountain \\
- Mill & 2 & 3 & - \\
Total & 1 & 3 & - \\
& 38 & 179 & - \\
\hline
\end{tabular}


Furthermore, since the failure mode is different between embankment and concrete dams, it affects the nature of the floods and the subsequent impact on people. Thus, application of the LL rates derived on the data, which is highly dominated by embankment dam failures, can potentially bias LL estimates in studies of concrete and masonry dams (e.g. large dams in Switzerland). Therefore, the LL rates distributions need to be adjusted to reflect study-specific characteristics such as the dam type and failure mode.

\subsection{Alternative LL rates distributions}

To construct alternative LL rates distributions that are representative for large dams in Switzerland, a specific dam failure data set of large concrete and masonry dams in mountain regions of OECD countries was compiled. For this purpose, the historical experience contained in PSI's Energyrelated Severe Accidents Database (ENSAD) was searched for relevant events.

The ENSAD database was developed at the Paul Scherrer Institute (PSI) in the 1990s (Hirschberg et al., 1998). Its goal is to enhance the comparative evaluation of different energy systems covering human health, environmental and economic impacts. ENSAD covers a broad range of full energy chains and continuous data collection ensures up-to-date information. Data from ENSAD are used for comparative risk assessment of energy technologies, to detect weak points in the energy infrastructure, and ultimately to support decision-making processes concerning energy supply options. For a detailed overview on ENSAD and its applications see Burgherr and Hirschberg (2014) or Burgherr et al. (2017).

The ENSAD comprises a worldwide dataset of more than 1,000 historical dam accidents in the period $1798-2017,70 \%$ of which were in OECD countries. Each accident record has a set of characteristics, which together provide an exhaustive description of the event. Categories for some characteristics, e.g. dam type, dimensions, are adopted from other databases (ICOLD, 1995), while for others they are created to meet specific needs of ENSAD.

For this study, the ENSAD hydropower dam section was queried for dam failures that meet the following criteria: dams made of concrete and masonry; dams located in mountain areas (to be representative for the Swiss topography); dams in OECD countries (to ensure similar levels of safety as in Switzerland, see Hirschberg et al. (1998)). Consequently, calculated LL rates based on dam failure data fulfilling the above criteria can be considered a reasonable approximation for Switzerland.
For each dam failure, data about the total number of fatalities (i.e. life loss) and the population in the downstream area were searched. The latter is indicated in ENSAD only as the name of the town nearest to the dam. However, for this study, relatively homogeneous areas, subPAR, had to be defined, i.e. the total PAR had to be subdivided in areas that are different in terms of the flood severity, warning time, or flood severity understanding. Therefore, additional information on downstream population was collected from local reports, interviews, newspapers, etc. to be able to define homogenous subPAR. For example, for the Gleno dam failure, a total of 356-500 fatalities were reported by different sources; however, the total number of people affected, and the number of fatalities was certainly known only for the Bueggio Village. The availability of the information for this village defined the decision to treat this village as one homogeneous subPAR. Finally, the life-loss rate, $\mathrm{P}$, was determined as the ration of LL to the population in the subPAR. For some subPAR, P was defined based on key words. For example, if the town was "washed out", than P of 0.99 was assumed with the confidence interval between 0.9 (people can survive even in a washout of the support surface) and 1 (resulted substantial destruction can lead to the complete population loss).

Furthermore, for each subPAR, the flood zone was defined based on warning time and flood severity. For this study, only one flood zone was assigned to each subPAR.

\subsection{Simulation example}

The simulation example was created to show that different LL rates defined in the model lead to different LL estimates. Therefore, to demonstrate the relevance of using LL rates that reflect dam and failure characteristic specifics for the study, e.g. studies for Swiss dams.

For the simulation, the failure of a hypothetical dam was assumed. The simulation example was built using the well-documented example project provided for the LIFESim program (USACE, 2017b). This project is not fully representative for the Swiss-dam study; however, certain data reflect the Swiss conditions. In particular, the dam-failure outflow hydrograph can be considered representative, since it reflects the instantaneous failure mode common for failures of concrete and masonry dams. For the instantaneous failure, no advance warning was initiated, i.e. dam failure warning was not issued prior to the dam failure. The area downstream of the dam is flat and open (see Figure 2), which corresponds to a hypothetical town at the end of a Swiss valley. Data for the structural inventories, emergency planning zones, road networks 


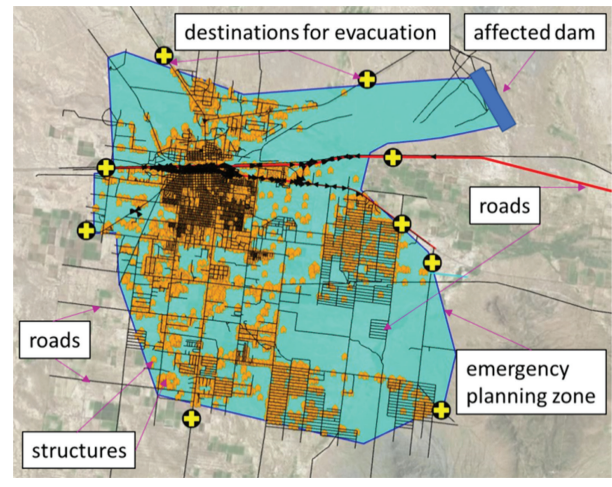

Figure 2. A map of the area flooded in the dam-failure event and symbols used for components of the LIFESim simulation (modified from USACE, 2017b).

and evacuation destinations were provided in the example project and originally taken from the sources mentioned in Section 2.1. The data for flow quantities were simulated in the HECRAS program (USACE, 2017d) and provided by USACE (2017b) as two-dimensional map.

Three simulations were created for this study. The first simulation corresponds to the application of the recommended LL rates by McClelland and Bowles (2002) (Section 2.2). The second simulation was run with the same model set-up except that the alternative LL rates were used (Section 2.3). For the third simulation, all downstream subPAR was assumed as a chance zone. This assumption was based on the methodology for determining PAR by the Swiss Federal Office of Energy (2017), whose procedure is based on PAR comprising the entire area affected by a dam-failure flood wave of at least $2 \mathrm{~m}$ height and intensity of at least $2 \mathrm{~m} 2 / \mathrm{s}$ in a period of $2 \mathrm{~h}$ after a complete failure. Furthermore, this assumption was supported by McClelland and Bowles (2002) suggesting that when the buildings are about 6 meters high (i.e. one or twostory dwellings that are common for Swiss towns), then the entire PAR (alternatively, subPAR) is considered as a chance zone.

For all three simulations the simulation were done for several times of the day, namely at 12 p.m. (midnight), 6 a.m., 12 a.m. (noon), 6 p.m., and using 100 model runs for each combination to ensure convergence of results.

\section{RESULTS}

\subsection{Alternative LL rates distributions}

For the LL rates analysis, a dataset of 14 failures of concrete and masonry dams (buttress, gravity, and arch) located in mountain regions of OECD countries was established (Table 2). Four events from Table 1 were also considered, namely the Zerbino, St. Francis, Vajont, and Vega de Terra dams.

In the established dataset, dam name, country, and the year of the accident are given. The fatalities are indicated as the total number of fatalities resulting from the dam failure and as the number of fatalities in the defined subPAR downstream of the dam. The population at risk is also given as the total number for the entire downstream area and as the number of people for the defined subPAR. All information sources are given in Table 2. Finally, the flood zones were assigned to the calculated $\mathrm{P}$ values using information about warning time and flood severity (Table 2). Assigned flood zones are specified for each subPAR as letter indices (Table 2).

For each flood zone, the alternative LL rates distribution was constructed using the corresponding calculated $P$ values (Figure 3 ). In addition, the confidence intervals were calculated for both alternative distributions using all the $\mathrm{P}$ values calculated based on different numbers of fatalities and people at risk found in the literature. Due to the lack of data for the safe zone among the failures in the new dataset, no fatalities were assumed in the safe zone.

For the alternative distribution of the chance zone, the range of $\mathrm{P}$ values is similar to the recommended $\mathrm{P}$, i.e. between 1 and 0.4 , with values of the alternative distribution potentially reaching 0.28 within its confidence interval (Figure 3 ). The recommended curve was built on a dataset with more realizations of high $\mathrm{P}$ with respect to the alternative distribution proposed in this study. This is shown for high $\mathrm{P}$ values (e.g. 0.8), which have a 0.9 and 0.7 frequency of exceedance for the recommended and alternative distributions, respectively. Furthermore, by considering the confidence intervals built for the alternative curve, the variability of possible $\mathrm{P}$ values is large for some $\mathrm{P}$ due to the limited data; thus, for the alternative distributions of the chance zone high $\mathrm{P}$ values can also increase to a frequency of 0.8 .

For the compromised zone, the range for the alternative LL rates is smaller than for the recommended rates and the highest $\mathrm{P}$ does not exceed 0.13 . However, taking into account the confidence intervals, realizations of 0.5 for $\mathrm{P}$ are also possible, which goes in line with the rates provided by McClelland and Bowles (2002).

\subsection{Simulation results}

Results for all three simulations are presented in Figure 4 and expressed in life loss as percentage of PAR (alternatively subPAR). The results are summarized using box plots showing the median 
Table 2. Extended dataset for failures of concrete and masonry dams located in mountain regions of OECD countries.

\begin{tabular}{|c|c|c|c|c|c|c|c|}
\hline $\mathrm{N}$ & Year & $\begin{array}{l}\text { Dam name (country) \& } \\
\text { subPAR name }\end{array}$ & $\begin{array}{l}\text { Fatalities in } \\
\text { subPAR }\end{array}$ & $\begin{array}{l}\text { Population } \\
\text { in subPAR }\end{array}$ & $\begin{array}{l}\text { Proportion } \\
\text { of Life } \\
\text { Loss, P }\end{array}$ & Warning & $\begin{array}{l}\text { Flood } \\
\text { Severity }\end{array}$ \\
\hline \multirow[t]{2}{*}{1} & 1923 & Gleno (Italy) & $356-500$ & 12,631 & - & & \\
\hline & & $\begin{array}{l}\text { Bueggio Village } \\
\text { (Bureau of Reclamation, 2015) }\end{array}$ & 209 & 500 & $0.42^{\mathrm{a}}$ & no & high \\
\hline \multirow[t]{2}{*}{2} & 1934 & Granadillar (Spain) & & & & & \\
\hline & & $\begin{array}{l}\text { (Gonzalez and Santamarta, } \\
\text { 2012) }\end{array}$ & 8 & - & $0.99^{\mathrm{a}}$ & & \\
\hline 3 & 1928 & Komoro (Japan) & 7 & - & - & & \\
\hline 4 & 2012 & Kopru (Turkey) & $\begin{array}{l}10 \\
\text { (Boston.com, } \\
\text { 2012) }\end{array}$ & $\begin{array}{l}300 \\
\text { (Haberturk, } \\
\text { 2012) }\end{array}$ & $0.0333^{\mathrm{b}}$ & & \\
\hline 5 & 1891 & Lynx Creek (USA) & 0 & - & 0 & & \\
\hline \multirow[t]{3}{*}{6} & 1959 & $\begin{array}{l}\text { Malpasset (France) (Graham, } \\
\text { 1999) }\end{array}$ & $400-550$ & 6000 & - & no & \\
\hline & & $100 \mathrm{ft}$ flood depth & 30 & 30 & $1^{\mathrm{a}}$ & & high \\
\hline & & . $10 \mathrm{ft}$ high entering Frejus & 391 & 6000 & $0.0652^{\mathrm{b}}$ & & medium \\
\hline \multirow[t]{2}{*}{7} & 1925 & Moyie River (USA) & 0 & - & 0 & & \\
\hline & & Puentes (Spain) & 680 & - & & & \\
\hline 8 & 1802 & - city of Lorca & $\begin{array}{l}608 \\
\text { (Saxena and } \\
\text { Sharma, } \\
\text { 2004) }\end{array}$ & $\begin{array}{l}4590 \\
\text { (Smedley et al., } \\
\text { 1845; Murcia } \\
\text { Today) }\end{array}$ & $0.132^{\mathrm{b}}$ & some & \\
\hline \multirow[t]{4}{*}{9} & 1928 & St Francis (USA) & $300-684$ & 2250 & - & some & \\
\hline & & $\begin{array}{l}\text { powerhouse N2 (McClelland } \\
\text { and Bowles, 2002) }\end{array}$ & 81 & & $0.99^{\mathrm{a}}$ & no & high \\
\hline & & Castaic Junction & $\begin{array}{l}\text { washed away } \\
\text { (Wikipedia, } \\
\text { 2017b) }\end{array}$ & & $0.99^{\mathrm{a}}$ & & \\
\hline & & $\begin{array}{c}\text { Edison tent camp at Kemp } \\
\text { (Rogers and James, }- \text { ) }\end{array}$ & 89 & 140 & $0.636^{\mathrm{a}}$ & no & high \\
\hline 10 & 1965 & Torrejon-Tajo (Spain) & 39 & 50 & $0.6^{\mathrm{a}}$ & & \\
\hline & & & $\begin{array}{l}\text { (Wikipedia, } \\
\text { 2017a) }\end{array}$ & $\begin{array}{l}\text { (Extremadura, } \\
\text { 2016) }\end{array}$ & & & \\
\hline \multirow[t]{3}{*}{11} & 1963 & $\begin{array}{l}\text { Vajont (Italy) (McClelland } \\
\text { and Bowles, 2002) }\end{array}$ & $1600-2600$ & 3000 & - & no & \\
\hline & & Longarone town & 1269 & 1348 & $0.941^{\mathrm{a}}$ & & \\
\hline & & lakeside communities & 158 & & $1^{\mathrm{a}}$ & & \\
\hline 12 & 1959 & $\begin{array}{l}\text { Vega de Tera (Spain) (Graham, } \\
\text { 1999) }\end{array}$ & $140-153$ & 415 & $0.347^{\mathrm{a}}$ & no & high \\
\hline \multirow[t]{2}{*}{13} & 1944 & Xuriguera (Spain) & 7 & - & - & & \\
\hline & & $\begin{array}{l}\text { farm house (La Vanguardia, } \\
\text { 1944) }\end{array}$ & 6 & 6 & $1^{\mathrm{a}}$ & & \\
\hline 14 & 1935 & Zerbino (Italy) & 130 & & - & & \\
\hline
\end{tabular}

a - chance zone; ${ }^{\mathrm{b}}$ - compromised zone.

of the modeled distributions and the bottom and top edges of the box indicating the 25 th and 75 th percentiles, respectively. The whiskers extend to the maximum and minimum of the data not considering outliers, and the outliers (i.e. points distant by twice or three times the standard deviation (Ruan et al., 2005)) are plotted individually.

For simulations 2 and 3, the results were calculated using the alternative distributions shown in
Figure 3 (solid lines). The confidence intervals of these distributions could not be taken into account due to specifics of the software settings.

The relative patterns of the results between different times of the day are similar across all three simulations. In particular, the highest values of $P$ were calculated at 12 p.m. and the lowest at 12 a.m. For the former, this could be explained by the fact that most people are asleep and not aware 


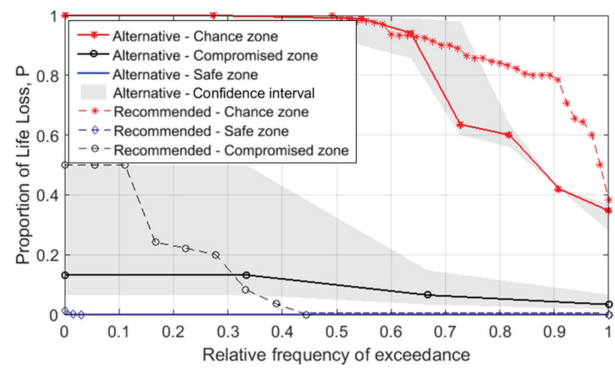

Figure 3. Historical LL rates distributions developed by McClelland and Bowles (2002) and LL rates distributions developed specifically for concrete \& masonry dams in mountain regions of OECD countries with the confidence intervals (minimal and maximal values).

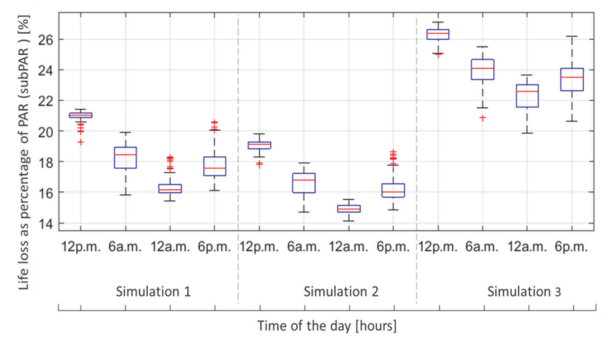

Figure 4. Simulation results for Life Loss as percentage of PAR: Simulation 1) using recommended life-loss rates by McClelland and Bowles (2002); Simulation 2) life-loss rates developed for dams in mountain areas; Simulation 3 ) test case with merged chance and compromised zone and safe zone without LL.

of a possible warning. On the other hand, at 12 a.m. most people are awake and at their duties; they can react faster to possible warning. The uncertainty range is higher for 6 a.m. and 6 p.m. results, because potentially at that time of the day people are traveling from home or back home; and it is quite uncertain how many people in traffic are exposed to the flood.

Comparing results between the first two simulations, the $\mathrm{P}$ values calculated in the second simulation are in general $10 \%$ lower than those calculated in the first simulation. This is due to the fact that, in the chance zone, the same $\mathrm{P}$ values have lower probabilities in the alternative distribution than in the recommended one, and in the compromised zone, the possible range of $\mathrm{P}$ values is in general lower (see Figure 3). The median values of $\mathrm{P}$ in the second simulation are shifted to lower values of the results range (i.e. distributions are left skewed) with respect to the first simulation. This can be explained by the fact that more severe $\mathrm{P}$ values in the chance and compromised zones in Figure 3 have lower frequency of exceedance (e.g. for a frequency of exceedance of $0.68, \mathrm{P}$ is equal to 0.8 and 0.9 in the chance zone for the alternative and recommended distributions, respectively). On the other hand, probabilities for lower values of $\mathrm{P}$ (i.e. closer to 0.4 ) do not differentiate to such a high extent.

Furthermore, uncertainty in the results of the second simulation is generally lower than in the first simulation, unless in the case of the simulation at 12 p.m. Generally lower uncertainty ranges can be explained by the fact that the alternative distributions are flatter (especially the one of the compromised zone); then, sampling from the $\mathrm{P}$ values in the alternative distribution could potentially result in the sample with smaller range of $P$ values.

Finally, comparing the results of the third simulation, it can be concluded that in general the defined $\mathrm{P}$ values are the highest among all simulations. Furthermore, uncertainty of the calculated values is significantly higher than in the results of the first two simulations. Moreover, the results show larger left skewness with respect to the other simulations results, because compromised zones became now chance zones and for all ranges of probabilities LL rates were higher. Thus, neglecting existence of compromised zones with their higher potential of people to survive, leads to potential overestimation of the overall life loss.

In general, lower rates for life losses reflected in the alternative distributions and results of the simulations are supported by the following circumstances. On the one hand, the alternative dataset of concrete and masonry dams is built exclusively for OECD countries, whereas the recommended LL rates include also events in non-OECD countries (e.g., China). Generally, higher population density downstream of non-OECD dams and differences in safety culture and awareness of people living downstream of non-OECD dams, could potentially result in higher life loss. On the other hand, mountain topography could leave higher survival chances for people located on higher altitudes in the downstream area. In contrast, in embankment dam failures, a flat area is commonly affected downstream of the dam; which makes the available shelter to be very remote.

\section{CONCLUSIONS}

To maintain or further improve the high safety levels of dams in Switzerland it is important to evaluate the performance of existing or planned risk mitigation measures at dams, and to estimate potential LL consequences of selected dam failure scenarios.

Generally, the LL estimation in dam risk assessment is a complex process, depending on many 
parameters and circumstances. Available dynamic modular systems for LL estimation (e.g. LIFESim) can overcome known limitations of the purely empirical methods, because they allow modeling of physical processes within the dam-failure event, e.g. evacuation, population distribution. These models can also go beyond LL estimates and, for example, define times of the day with the highest risk for PAR, as it was demonstrated in the current study.

Furthermore, this study demonstrated the importance of adjusting the LL rates distributions to reflect study-specific characteristics such as the dam type, failure mode, etc. The LL rates derived from historical failures of concrete and masonry dams in mountain regions of OECD countries had different shapes and frequency ranges than the generic ones in LIFESim. The LL estimates calculated using the recommended and alternative LL rates gave different LL estimates in the simulation example of the hypothetical dam failure carried out in this study.

In summary, the importance of defining studyspecific alternative LL rates distributions for dam risk assessment was demonstrated. Potential future extensions rely on the reduction of the width of the confidence intervals for the alternative LL-rate distributions considered representative for large concrete dams in Switzerland. To reduce the rather large uncertainty ranges, continuous update of information is suggested. In particular, more dam accidents need to be included and better information on subPAR, flood severity and warning availability to be provided for the events in the existing list of historical failures of concrete and masonry dams. Finally, the concept will be improved and implemented in more details to a real case study reflecting Swiss conditions.

\section{ACKNOWLEDGMENT}

This research project is part of the National Research Programme "Energy Turnaround" (NRP 70) of the Swiss National Science Foundation (SNSF). Further information on the National Research Programme can be found at www.nrp70.ch. It is also integrated within the activities of the Swiss Competence Center on Energy Research - Supply of Electricity (SCCER SoE). The authors express their sincere thanks to Dr. Christopher Robinson, who provided valuable feedback to this work.

\section{REFERENCES}

Boston.com. 2012. Official: 10 missing in dam flooding in Turkey. http://articles.boston.com/2012-02-24/ news/31096589_1_dam-burst-hatch-rains.
Bowles, D.S. 2007. Life Loss Estimation for RAMCAP, Appendix D,. Conventional Dams and Navigation Locks, Sector-Specific Guidance (SSG), Risk Analysis and Management for Critical Asset Protection (RAMCAP) Phase III for Dams, Locks and Levees.

British Columbia, H. 2006. Life Safety Model System V1.0, Guidelines, Procedures, Calibration and Support Manual., Rep. No. Technical Report Engineering Report E310: British Columbia Hydro.

Brown, C.A. \& Graham, W.J. 1988. Assessing the threat to life from dam failure. JAWRA Journal of the American Water Resources Association, 24: 1303-1309.

Bureau of Reclamation 2015. Reclamation Consequence Estimating Methodology: Dam Failure and Flood Event Case History Compilation U.S. Department of the Interior.

Burgherr, P. \& Hirschberg, S. 2014. Comparative risk assessment of severe accidents in the energy sector. Energy Policy, 74: S45-S56.

Burgherr, P., Spada, M., Kalinina, A., Hirschberg, S., Kim., W., Gasser, P. \& Lustenberger, P. 2017. The Energy-related Severe Accident Database (ENSAD) for comparative risk assessment of accidents in the energy sector. In: Cepin, M.B., R. (ed.) Safety and Reliability - Theory and Applications. UK: CRC Press, Taylor \& Francis Group.

Costa, J.E. 1985. Floods from dam failures, Denver, Colorado: United States Department of the Interior, Geological Survey.

ESRI. 2017. Environmental Systems Research Institute, ESRI products, software, and services. ESRI, Redlands, CA.

Extremadura, e. P. 2016. 51 años de la tragedia de la presa de Torrejón.

Federal Emergency Management Agency, F. 2003. HAZUS. Comprehensive Data Management System (CDMS) Data Dictionary, For Use with Hazus-MH Version 2.1: FEMA, Mitigation Division, Washington, D.C.

Froehlich, D.C. 1995. Peak Outflow from Breached Embankment Dam. Journal of water Resources Planning and management, 121.

Gonzalez, J.G. \& Santamarta, J.C. 2012. Technical development and characteristics of dam engineering in the Canary Islands. Revista de Obras Públicas: 33-50.

Graham, W.J. 1999. A Procedure for Estimating Loss of Life Caused by Dam Failure, Rep. No. DSO-99-06, Denver, Colorado: Sedimentation \& River Hydraulics.

Haberturk. 2012. Adana dam cover burst. Dam failure in Adana. http://www.haberturk.com/yasam/ haber/719281-adanada-baraj-faciasi-galeri.

Hirschberg, S., Spiekerman, G. \& Dones, R. 1998. Severe accidents in the energy sector-first edition. PSI Report 98-16: Paul Scherrer Institut.

ICOLD 1995. Dam Failures Statistical Analysis. Bulletin 99, Paris, France.

ICOLD 2016. Dictionary. International Commission on Large Dams. http://www.icold-cigb.net/GB/Dictionary/ dictionary.asp.

Kalinina, A., Sacco, T., Spada, M. \& Burgherr, P. 2017. Risk assessment for dams of different types and purposes in OECD and non-OECD countries with a focus on time trend analysis. e-Proceedings of Hydro 2017 Conference "Shaping the future of Hydropower", 13.01, Spain. 
La Vanguardia. 1944. Ha desaparecido el pantano de Xuriguera. La Vanguardia, Espanola, Sebado, 26 de febrero de 1944.

Lee, R., Hu, P.S., Neal, D.M., Ogles, M.R., Sorensen, J.H. \& Trumble, D.A. 1986. Predicting loss of life from floods, Institute for Water Resources, US Army Corps of Engineers.

McClelland, D.M. \& Bowles, D. 2000. Estimating life loss for dam safety and risk assessment: Lessons from case histories. Proc. 2000 Annual USCOLD Conference, U.S. Society on Dams, 2000 Denver, CO.

McClelland, D.M. \& Bowles, D.S. 2002. Estimating life loss for dam safety risk assessment - a review and new approach Logan, Utah: Institute for Dam Safety Risk Management Utah State University.

Murcia Today. Collapse of the Puentes dam in Lorca (1802). https://murciatoday.com/lorca-commemoratesthe-collapse-of-the-puentes-dam_11502-a.html.

Rogers, J.D. \& James, K. -. Mapping the St. Francis dam outburst flood with geographic information systems: University of Missouri-Rolla.

Ruan, D., Chen, G., Kerre, E.E. \& Wets, G. 2005. Intelligent Data Mining: Techniques and Applications.

Salvati, P., Petrucci, O., Rossi, M., Bianchi, C., Pasqua, A.A. \& Guzzetti, F. 2018. Gender, age and circumstances analysis of flood and landslide fatalities in Italy. Science of The Total Environment, 610-611: 867-879.
Saxena, K.R. \& Sharma, V.M. 2004. Dams: Incidents and Accidents: CRC Press.

Smedley, E., Rose, H.J. \& Rose, H.J. 1845. Encyclopaedia Metropolitana, Or, Universal Dictionary of Knowledge.

Swiss Federal Office of the Energy SFOE 2017. Methodik zur Bestimmung der Anzahl gefährdeter Personen (people at risk PAR) zur Abschätzung der hohen Gefahr (Version 1.0).

TRB 2000. Highway capacity manual. Technical report, Washington, D.C.: Transportation Research Board, National Research Council.

USACE 2017a. HEC-LifeSim 1.0. U.S. Army Corps of Engineers, Hydrologic Engineering Center.

USACE. 2017b. HEC-LifeSim 1.0 Example Data. U.S. Army Corps of Engineers, Hydrologic Engineering Center. http://www.hec.usace.army.mil/software/heclifesim/downloads.aspx.

USACE 2017c. HEC-RAS 5.0.3. U.S. Army Corps of Engineers, Hydrologic Engineering Center.

USACE 2017d. The Hydrologic Engineering Center's (CEIWR-HEC) River Analysis System (HEC-RAS). U.S. Army Corps of Engineers, Hydrologic Engineering Center.

Wikipedia. 2017a. Desastre de Torrejón. https:// es.wikipedia.org/wiki/Desastre_de_Torrej $\% \mathrm{C} 3 \% \mathrm{~B} 3 \mathrm{n}$.

Wikipedia. 2017b. St. Francis Dam. Available: https:// en.wikipedia.org/wiki/St._Francis_Dam. 